\title{
Technical Feasibility of a Guidetube for Various Endoscopic Procedures in Human Gastrointestinal Simulators
}

\author{
Dong Seok Lee ${ }^{1,2}$, Byeong Gwan Kim ${ }^{1,2}$, Kook Lae Lee ${ }^{1,2}$, Yong Jin Jung ${ }^{1,2}$ and Ji Won Kim ${ }^{1,2}$ \\ ${ }^{1}$ Department of Gastroenterology, SMG-SNU Boramae Medical Center, ${ }^{2}$ Department of Internal Medicine, Seoul National University of \\ College of Medicine, Seoul, Korea
}

Background/Aims: Many gastrointestinal (GI) endoscopic procedures are difficult and cumbersome owing to the limitation of currently available endoscopic devices. This study aimed to develop an endoscopic guidetube for multipurpose endoscopic procedures and assess its use in a realistic GI endoscopic simulator.

Methods: The guidetube used is a soft overtube composed of neoprene and is designed to assist various endoscopic procedures on demand. In total, 15 types of procedures were performed in GI simulators. Four procedures were performed in the stomach model and 11 in the colon model. The procedures include repeated endoscopic insertion and foreign body removal in various positions. The mean insertion and procedure time were assessed in each session. All procedures were performed by 5 expert endoscopists.

Results: Endoscopic procedures with the new guidetube were faster and more effective than the conventional endoscopic techniques. The mean insertion time of the endoscope with the guidetube was significantly shorter than that without the guidetube. The guidetube was safely inserted without scratch using low pushing force. Objects of various sizes larger than the endoscopic channel were easily removed by the guidetube-assisted endoscopic procedures.

Conclusions: This preliminary study shows that guidetube-assisted endoscopic procedures are faster, easier, safer and cheaper than conventional endoscopic procedures. Clin Endosc 2019;52:247-251

Key Words: Endoscopic guidetube; Foreign body removal; Multiple large polyp removal

\section{INTRODUCTION}

Over the last decade, esophagogastroduodenoscopy and colonoscopy have been widely acknowledged as optimal modalities for the examination and treatment of various gastrointestinal (GI) diseases because of their clinical and economic benefits compared with surgery. However, these procedures require much time and effort and include a significant risk for

Received: August 26, 2018 Revised: October 2, 2018

Accepted: October 2, 2018

Correspondence: Ji Won Kim

Department of Gastroenterology, SMG-SNU Boramae Medical Center, Seoul National University of College of Medicine, 20 Boramae-ro 5-gil, Dongjak-gu, Seoul 07061, Korea

Tel: +82-2-870-2221, Fax: +82-2-870-3866, E-mail: kjwjor@snu.ac.kr ORCID: https://orcid.org/0000-0002-1214-5544

(c) This is an Open Access article distributed under the terms of the Creative Commons Attribution Non-Commercial License (http://creativecommons.org/ licenses/by-nc/3.0) which permits unrestricted non-commercial use, distribution, and reproduction in any medium, provided the original work is properly cited. the patient. Especially difficult cases of endoscopic removal of foreign bodies and malignant lesions are very burdensome to both the patient and doctor. ${ }^{1}$ Therefore, a new approach for these procedures is needed. However, current endoscopic platforms are limited by the narrow and complex GI tract. The outer diameters of a conventional endoscope are $1 \mathrm{~cm}$ in the gastroscope and $1.2 \mathrm{~cm}$ in the colonoscope. The endoscope channel is a tunnel space in which an external accessory tool can enter the GI tract. Conventional channel sizes are $2.8 \mathrm{~mm}$ for the gastroscope and $3.2 \mathrm{~mm}$ for the colonoscope. Endoscopic resection (e.g., endoscopic mucosal and submucosal resection) is a very common procedure and reduces the mortality from GI cancer. ${ }^{2-5}$ However, many procedures are required in cases of multiple polyps larger than the endoscopic channel using conventional methods. ${ }^{6,7}$ Such repeated insertions are difficult for the patient and operator and can cause musculoskeletal disorders in endoscopists. Several overtube devices have been designed to facilitate endoscopy. ${ }^{8-12}$ However, the 
practical use of overtubes in hospitals is limited because of the incidence of various complications such as pharyngeal and esophageal perforation, variceal rupture, overtube separation, transient vocal cord paralysis, pneumomediastinum, and tracheal compression. ${ }^{9,13-18}$ In addition, conventional simple overtubes are not used in Korea because they are expensive, except for esophageal drainage and variceal ligation. Hence, a new guidetube was developed to overcome these limitations. This study evaluated the feasibility of new endoscopic procedures using this guidetube.

\section{MATERIALS AND METHODS}

\section{Participants}

In July 2018, 5 expert endoscopists working at SMG-SNU Boramae Medical Center (Seoul, Korea) participated in this study. In each simulation, a timer was started when the scope was inserted into the entrance and stopped when the scope reached its target position.

\section{Newly developed endoscopic guidetube}

The new guidetube was designed to enhance secure insertion into the target area. It is composed of inner and outer tubes (Fig. 1). The outer tube is made of silicone while the inner tube is composed of a plastic channel. The outer tube has a $15-\mathrm{mm}$ outer diameter and $13-\mathrm{mm}$ inner diameter. To reduce mucosal trauma caused by rigidity of the tube, silicone was used for the tube material, as it will be inserted in the urethra and bladder, which are sensitive to trauma. The plastic channel allows the passage of various endoscopic instruments (biopsy forceps, snare, etc.). The basic guidetube is $30-\mathrm{cm}$ long and is mainly used for the stomach and sigmoid colon. However, it can be manufactured or cut into various lengths by the manufacturer or endoscopist. Guidetubes of $80 \mathrm{~cm}$ and $60 \mathrm{~cm}$ in length can be used for the ascending and transverse colons.

\section{Procedures using the guidetube in the stomach and colon simulator}

We performed a series of endoscopic procedures with a gastroscope (GIF-260; Olympus, Tokyo, Japan) in 2 GI simulators: Endoscopy Gastrointestinal ERCP Upper Gi Training Simulator Deluxe-1 and Colonoscopy Training Simulator Manikin (Buyamag Inc., Carlsbad, CA, USA).

The guidetube was inserted and fixed at the target site of the stomach or colon under endoscopy guidance. Fixed sites included the sigmoid colon (anal verge $[\mathrm{AV}]: 30 \mathrm{~cm}$ ), descending colon (AV: $50 \mathrm{~cm}$ ), transverse colon (AV: $60 \mathrm{~cm}$ ), ascending colon (AV: $70 \mathrm{~cm}$ ), and esophagus (upper incisor teeth: 30 $\mathrm{cm}$ ). Five expert endoscopists repeatedly inserted the guidetube at the above sites for 20 times. For more practical testing, large masses (large pork loaf, pen cover) were placed on the above points, and endoscopic retrieval using the guidetube was repeated 20 times.

A total of 15 endoscopic procedures were performed in each GI simulator (Fig. 2): 4 repeated endoscopic insertions (2 conventional and 2 guidetube-assisted) in a stomach model, 8 repeated endoscopic insertions (4 conventional and 4 guidetube-assisted) in a colorectal model, and retrieval of multiple foreign bodies (1 conventional and 1 guidetube-assisted), multiple polyps ( 1 conventional and 1 guidetube-assisted), and large amounts of food (1 conventional and 1 guidetube-assisted).

\section{Statistical analysis}

Statistical analysis was performed using the paired, one-sided Student's $t$-test. A $p$-value $<0.05$ was considered to be statistically significant. Insertion time was calculated based on each stomach and colon position using the guidetube. The effectiveness of the endoscopic procedure using the guidetube was verified by comparing the results with standard endoscopic insertion at SMG-SNU Boramae Medical Center.
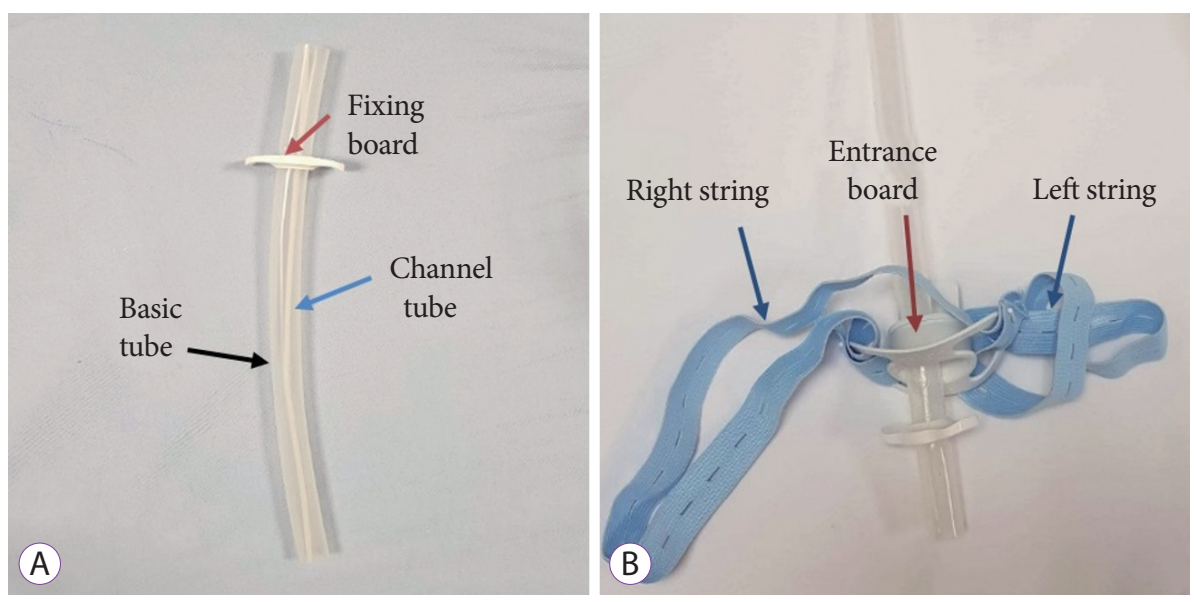

Fig. 1. This photo shows the guidetube for various endoscopic procedures. The guidetube system has 2 components, the guidetube and locking portion. (A) The guidetube is composed of a basic tube, channel tube, and fixing board. (B) The locking portion is composed of 2 strings and an entrance board. The guidetube is fixed through the entrance board. The 2 strings fasten the guidetube to the body. 


\section{RESULTS}

The primary outcome measure was the total procedure time. Endoscopic insertion times were reduced by approximately $70 \%$ using the guidetube. The mean insertion time of endoscope with the guidetube was significantly shorter than that without the guidetube: distal esophagus $(3.2 \pm 0.5 \mathrm{sec}$ vs. $5.4 \pm 1.8 \mathrm{sec})$; distal gastric antrum $(4.4 \pm 0.5 \mathrm{sec}$ vs. $5.4 \pm 1.8 \mathrm{sec})$; descending colon ( $4 \pm 1 \mathrm{sec}$ vs. $17.2 \pm 1.9 \mathrm{sec}$ ); transverse colon $(7 \pm 1.2 \mathrm{sec}$ vs. $25.8 \pm 1.5 \mathrm{sec})$; and cecum $(8.4 \pm 0.89 \mathrm{sec}$ vs. $60 \pm 8.4$
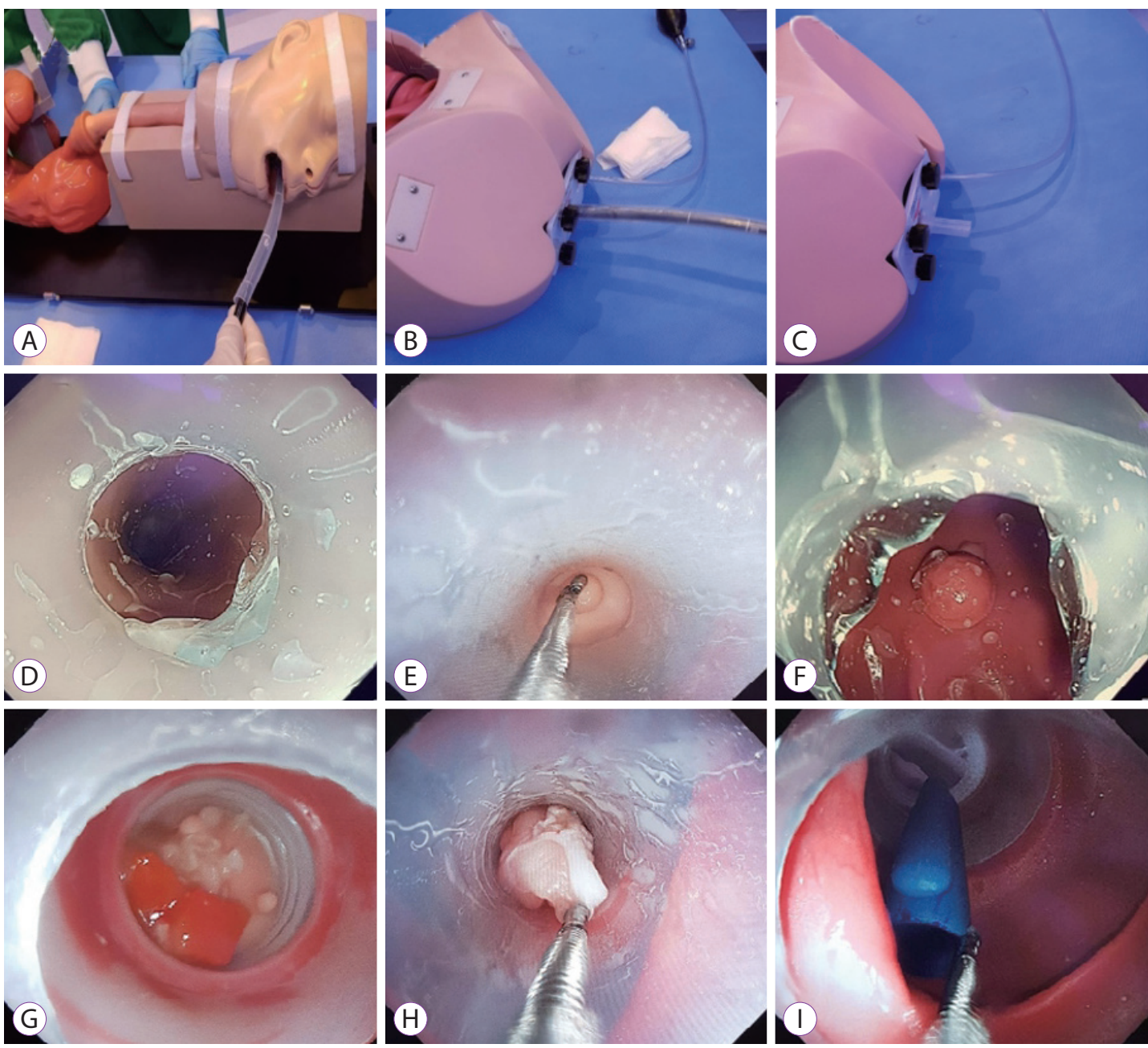

Fig. 2. Various endoscopic procedures using the guidetube. The guidetube is mounted on the conventional endoscope and inserted into the gastrointestinal lumen. After fixing the guidetube into the simulator entrance, the endoscope is removed. Examples of various materials removed using the new guidetube from the gastrointestinal tract. (A) An endoscope equipped with a guidetube is inserted into the stomach simulator. (B) An endoscope equipped with a guidetube is inserted into the colon simulator. (C) Only the guidetube is fixed in the colon. (D) The guidetube is mounted on the sigmoid colon. (E) Small polyps, (F) 1-cm polyps, (G) food material, (H) 2-cm polyp, and (I) foreign body (cap of pen).

Table 1. Outcomes of Endoscopic Procedures in the Stomach and Colon

\begin{tabular}{lccc}
\hline Site & Insertion time without guidetube $(\mathbf{s e c})$ & Insertion time with guidetube $(\mathbf{s e c})$ & $\boldsymbol{p}$-value \\
\hline Distal esophagus & $5.4 \pm 1.8$ & $3.2 \pm 0.5$ & 0.002 \\
Distal gastric antrum & $7.8 \pm 1.9$ & $4.4 \pm 0.5$ & $<0.001$ \\
Descending colon & $17.2 \pm 1.9$ & $4 \pm 1$ & $<0.001$ \\
Transverse colon & $25.8 \pm 1.5$ & $7 \pm 1.2$ & $<0.001$ \\
Cecum & $60 \pm 8.4$ & $8.4 \pm 0.9$ & $<0.001$ \\
\hline
\end{tabular}

Data are presented as mean \pm standard deviation; paired $t$-test applied; $p<0.05$ is statistically significant. 
sec). Details are presented in Table 1 and Fig. 3.

The secondary outcome measure was safety and efficiency. The guidetube was safely inserted without scratch using low pushing force. Its pushing force was lower than the simple overtube (proximal esophagus: $1.5 \pm 0.1 \mathrm{~kg}$ vs. $4.4 \pm 0.1 \mathrm{~kg}$ ). Objects of various sizes larger than the endoscopic channel were easily removed using the guidetube-assisted endoscopic procedures. The mean time to retrieve a $2-\mathrm{cm}$ polyp with the guidetube was significantly shorter than that without a guidetube (descending colon: $15.2 \pm 1.5 \mathrm{sec}$ vs. $36 \pm 3.1 \mathrm{sec}$ ).

\section{DISCUSSION}

Many endoscopic procedures (removal of multiple large polyps or sharp foreign bodies) are challenging and time-consuming. They require repeated endoscopic insertion, which causes much pain for the patient and repetitive motion injuries for the operator. Consequently, many overtubes have been developed to make endoscopic procedures easier. ${ }^{12}$ Most conventional and simple overtubes, such as the Guardus overtube - gastric (US Endoscopy Group, Inc., Mentor, OH, USA), have been used to enable repeated endoscopic insertion. However,

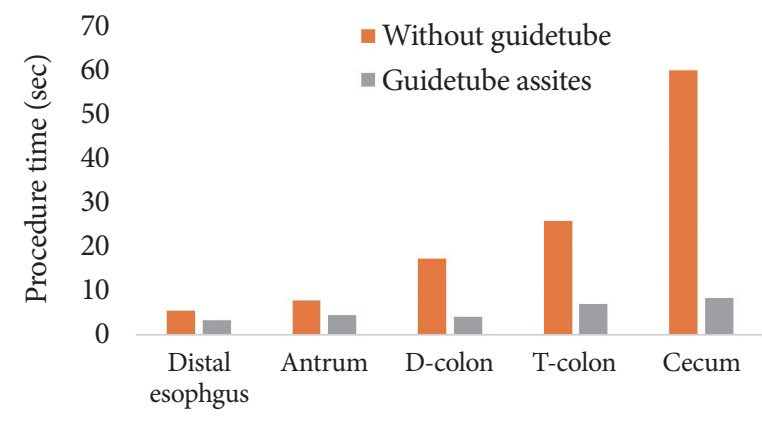

Edge point of guidetube

Fig. 3. Summarized results of the efficacy of repetitive endoscopic insertion. Endoscopic insertion using the guidetube was significantly efficient than conventional endoscopic insertion. these simple overtubes are currently limited in use due to the high risk of intestinal perforation because of the material's rigidity. ${ }^{12,14,15,17,19}$ Most overtubes are short; hence, it is difficult to get into deep areas such as the small intestine.

We developed a guidetube that is made of silicone to overcome the disadvantages of the rigid types. Silicone is soft and flexible and can be safely used in many organs. Therefore, the new tube can be used more extensively and complications can be minimized. Insertion of the guidetube is safe and simple. There are 2 ways to insert it: First, the endoscope and guidetube are inserted together simultaneously. Second, the guidetube is inserted along with the endoscope.

The optimal length of the guidetube selected for the upper GI tract was $30 \mathrm{~cm}$ because insertion in the upper GI tract is relatively easy except in the hypopharynx, which is a mucosa-lined muscular tube surrounded by several muscle walls. Likewise, the optimal length of the guidetube selected for the lower GI tract was $30 \mathrm{~cm}$ because endoscopic insertion in the lower GI tract is relatively easy except for the junction of the sigmoid and descending colon. However, the length can vary based on the user's needs and patient's condition, such as a history of surgery or bowel deformity. In cases of multiple large polyps in the ascending colon, the optimal length of the guidetube is $70 \mathrm{~cm}$. because the guidetube is inexpensive, users can adjust the guidetube length.

The new guidetube can be used to perform various procedures that were previously performed using an overtube, which presents many advantages. These include a reduction in the incidence of complications in the existing overtube, the ability for the operator to change the length as needed, and the low cost to manufacture, which means the guidetube can be used as a basis for all treatment endoscopes. In addition, complicated procedures can be performed by placing ancillary devices in the channels located within the guidetube. Table 2 shows endoscopic procedures performed easily and quickly through the guidetube.

This study had some limitations. First, all tests were performed in human GI simulators not in patients. Peristalsis,

Table 2. Indication for the Guidetube for Gastrointestinal Endoscopy

\begin{tabular}{|c|c|}
\hline Removal of large, sharp foreign bodies & $\begin{array}{l}\text { Mucosal protection from sharp objects such as blade, gastrointestinal stent, mussel shell, } \\
\text { or fish bone }\end{array}$ \\
\hline Incorporation with specialized endoscopes & $\begin{array}{l}\text { Large polyp removal for ESD or EMR, repetitive endoscopic insertion, easy manipulation } \\
\text { of endoscopy or NOTES }\end{array}$ \\
\hline Access for endoscopic drainage & Bulk food material for gastroparesis, large hematoma, blood \\
\hline Accessory device insertion & $\begin{array}{l}\text { Insertion of secondary accessory forceps or snare through the channel tube of guidetube } \\
\text { in addition to the endoscopic channel (Fig. 1A) }\end{array}$ \\
\hline Colonic decompression & Sigmoid volvulus, pseudo-obstruction \\
\hline
\end{tabular}

EMR, endoscopic mucosal dissection; ESD, endoscopic submucosal dissection; NOTES, natural orifice transluminal endoscopic surgery. 
elasticity, and movement of a real human GI tract were not completely reproduced. Endoscopic procedures in a human GI simulator are easier to perform than in a real human GI tract. However, by choosing realistic simulators, this bias was minimized. Second, all tests were performed in easily accessible locations. However, the reason for choosing uncomplicated fixation positions was to exclude other factors affecting the endoscopic procedure time. Future studies in animals and humans should be conducted to overcome the limitations of the GI simulator in this study design.

In conclusion, all tests were performed quickly and safely using the new guidetube. Endoscopic procedures using the guidetube are simple and accessible methods for assisting the endoscopic removal of large multiple polyps and sharp foreign bodies in the GI tract. The guidetube can be used as a guide tunnel to approach the GI tract when a conventional approach is difficult. It is considered as an effective tool for improving the endoscopic approach with a low risk to patients compared with conventional approaches.

\section{Conflicts of Interest}

The authors have no financial conflicts of interest.

\section{Acknowledgements}

We would like to thank Editage (https://www.editage.co.kr) for the assistance in English language editing.

\section{REFERENCES}

1. Birk M, Bauerfeind P, Deprez PH, et al. Removal of foreign bodies in the upper gastrointestinal tract in adults: European Society of Gastrointestinal Endoscopy (ESGE) clinical guideline. Endoscopy 2016;48:489496.

2. Hong S, Suh M, Choi KS, et al. Guideline adherence to colonoscopic surveillance intervals after polypectomy in Korea: results from a nationwide survey. Gut Liver 2018;12:426-432.

3. Uraoka T, Saito Y, Matsuda T, et al. Endoscopic indications for endo- scopic mucosal resection of laterally spreading tumours in the colorectum. Gut 2006;55:1592-1597.

4. Wedi E, Orlandini B, Gromski M, et al. Full-thickness resection device for complex colorectal lesions in high-risk patients as a last-resort endoscopic treatment: initial clinical experience and review of the current literature. Clin Endosc 2018;51:103-108.

5. Winawer SJ, Zauber AG, Ho MN, et al. Prevention of colorectal cancer by colonoscopic polypectomy. The National Polyp Study Workgroup. N Engl J Med 1993;329:1977-1981.

6. Klein A, Bourke MJ. Advanced polypectomy and resection techniques. Gastrointest Endosc Clin N Am 2015;25:303-333.

7. Lee SP, Sung IK, Kim JH, Lee SY, Park HS, Shim CS. Risk factors for incomplete polyp resection during colonoscopic polypectomy. Gut Liver 2015;9:66-72.

8. Goldschmiedt M, Haber G, Kandel G, Kortan P, Marcon N. A safety maneuver for placing overtubes during endoscopic variceal ligation. Gastrointest Endosc 1992;38:399-400.

9. Hawari R, Pasricha PJ. Going for the loop: a unique overtube for the difficult colonoscopy. J Clin Gastroenterol 2007;41:138-140.

10. Raju GS, Pasricha PJ. ShapeLock: a rapid access port for redeployment of a colonoscope into the proximal colon to facilitate multiple polypectomies in a single session. Gastrointest Endosc 2005;61:768-770.

11. Shin JS, Sheu BS, Lin XZ, Chen CY, Leow TC. Longitudinal linear-incised overtube for endoscopic removal of larger ingested foreign bodies. Gastrointest Endosc 1995;41:618.

12. ASGE Technology Committee, Tierney WM, Adler DG, et al. Overtube use in gastrointestinal endoscopy. Gastrointest Endosc 2009;70:828-834.

13. Berkelhammer C, Madhav G, Lyon S, Roberts J. "Pinch" injury during overtube placement in upper endoscopy. Gastrointest Endosc 1993;39:186-188.

14. Dinning JP, Jaffe PE. Delayed presentation of esophageal perforation as a result of overtube placement. J Clin Gastroenterol 1997;24:250-252.

15. el-Newihi HM, Mihas AA. Esophageal perforation as a complication of endoscopic overtube insertion. Am J Gastroenterol 1994;89:953-954.

16. Groenen MJ, Moreels TG, Orlent H, Haringsma J, Kuipers EJ. Acute pancreatitis after double-balloon enteroscopy: an old pathogenetic theory revisited as a result of using a new endoscopic tool. Endoscopy 2006;38:82-85.

17. Holderman WH, Etzkorn KP, Patel SA, Harig JM, Watkins JL. Endoscopic findings and overtube-related complications associated with esophageal variceal ligation. J Clin Gastroenterol 1995;21:91-94.

18. Jeffries MA, Scheiman JM. Overtube separation. Gastrointest Endosc 1998;47:435-436.

19. Levy R, Kaur S, Uzer M. Separation of an overtube from the bite block during band ligation of esophageal varices. Gastrointest Endosc 1997;46:66-68. 